\title{
Minding the gaps: Comparing engineering research output and library hold- ings at four large universities
}

\section{Michelle Spence, University of Toronto}

Michelle Spence is a Reference \& Instruction Librarian at the University of Toronto's Engineering \& Computer Science Library. She holds a HBSc (2004) and a MISt (2007), both from the University of Toronto. She has held positions in academic and public libraries, as well as a corporate setting.

Amber Saundry, University of British Columbia, Vancouver

Amber Saundry is a Reference Librarian for science and engineering at the University of British Columbia's (UBC) Woodward Library. She holds a B.Sc. (2008) and received her M.L.I.S. from UBC in 2014.

\section{Mrs. Tara Mawhinney, McGill University}

Tara Mawhinney is a liaison librarian at McGill University's Schulich Library of Science and Engineering in Montreal, Quebec. Her research interests include information literacy competencies, collection analysis, discovery search tools, and library services for international students.

\section{Sarah Jane Dooley, Dalhousie University}

Sarah Jane Dooley is Head of Reference \& Research Services, and Promotions \& Liaison Librarian at Dalhousie University's Sexton Design \& Technology Library in Halifax, Nova Scotia.

\section{Mr. Eugene Barsky, University of British Columbia, Vancouver}

Eugene Barsky is the Research Data Librarian at the University of British Columbia (UBC). He is interested in engineering information, data management in the physical sciences and has published extensively in the library literature. 


\title{
Minding the gaps: Comparing engineering research output and library holdings at four large universities
}

\begin{abstract}
This study compares serial subscriptions and holdings of conference proceedings at four large academic engineering libraries in Canada to determine where researchers are publishing, with the goal of better aligning library holdings with research output. Subject areas covered in the study consist of civil and mechanical engineering.

The Web of Science (WoS) database was used to extract articles and conference proceedings published by researchers between 2008 and 2013. WoS was selected because it captures more accurate affiliation information for each participating author than other databases such as ASCE, Compendex, and IEEE. Bibliographic data was extracted from the WoS database for the civil and mechanical engineering departments in four engineering faculties and was matched with current holdings, including serials and conference subscriptions. The gaps were analyzed to determine whether additional serials alignments are required. The findings of this study indicate that each of the libraries held at least $80 \%$ of the source titles where faculty published, although coverage of journals was stronger than that of conferences.
\end{abstract}

The current study discusses how four large academic libraries have dealt with these collection challenges, and how individually (and as a group) we have aligned our engineering serials collections to our users' publishing patterns and needs.

\section{Introduction}

Academic libraries are under tremendous pressure within their collections budgets, especially in Canada, where over the last two years we have lost approximately $10 \%$ of our purchasing power due to currency exchange rates. With these factors in mind, it is increasingly important that libraries make informed decisions about the content they are subscribing to and purchasing. One way is to examine where faculty at our institutions are publishing.

This study examines faculty publications from Dalhousie University, the University of British Columbia, McGill University and the University of Toronto. The authors of this study chose faculty publications in particular because the four libraries involved are all members of the Canadian Association of Research Libraries, and are considered to be research-intensive universities. As such, faculty publication patterns are an important consideration when making collections decisions in our libraries. This study compares serial subscriptions and holdings of conference proceedings at four large academic engineering libraries in Canada to determine 
where researchers are publishing, with the goal of better aligning library holdings with research output.

The WoS database (including the Conference Proceedings Citation Index- Science (CPCI-S) -1990-present) was used to extract articles and conference proceedings published by researchers at each institution between 2008 and 2013. WoS was selected because it captures affiliation information for each participating author, something that many other engineering databases such as ASCE or IEEE do not provide, and it is a database to which each of the four institutions subscribes. Subject areas covered in the study consist of civil and mechanical engineering. These two departments were chosen because they are large departments at each of the four participating universities and several of the librarians involved in this study work in libraries responsible for meeting the collection and liaison needs of these departments. Researchers extracted citation data from the WoS database for our departments in the four engineering schools and verified these against current serials subscriptions and holdings of conference proceedings. We analyzed the gaps to determine whether or not greater alignment of serials and conference proceedings was required.

The study examines titles in which mechanical and civil engineering faculty and other researchers publish frequently, as well as titles missing from our collections. We suspected that missing titles would be mostly in the form of conference proceedings rather than journal articles. Given that a previous study by Young suggests that conferences in engineering have a short shelf life (he states that "only $10 \%$ of all conference proceeding citations were older than 17 years"1), having missing titles in the form of conferences seems less problematic. The current study examined not only the percentage of missing titles at each institution but also the breakdown of source titles by format to determine if they were predominantly journal or conferences.

This study identifies how our four large academic libraries have dealt with collection challenges, and how individually (and as a group) we have aligned our engineering serials collections to our users' publishing patterns and needs.

\section{Literature Review}

There are many citation studies that use various methodologies to gather data and compare it to library holdings. In fact, Hoffmann and Doucette's ${ }^{2}$ review article on citation analysis methodologies provides a list of citation analysis studies in the appendix that also includes variables analyzed in each study such as citation age, subject area, comparison with library holdings, etc. Although there are many articles that discuss what faculty cite in their reference lists and compare these results to library holdings (such as Currie \& Monroe-Gulick ${ }^{3}$; Cusker ${ }^{4}$; Kraus $^{5}$; Price ${ }^{6}$; Ralston, Gall, \& Brahmi ${ }^{7}$; Rethlefsen ${ }^{8}$; Young ${ }^{1}$ ), the current literature review will focus on studies that have measured where faculty in science and engineering choose to publish in comparison with library holdings. 
The primary reason the current study examines source titles of faculty publications is because previous literature suggests that there is a direct correlation between where faculty publish and what they cite. Lascar and Mendelsohn's study identified that "the journals where [faculty] have published their recent work correspond closely with those they cite, indicating a close match in relative usefulness" 9 . Using source publication provides a direct measure of importance of a specific publication to a specific university community. According to LaBonte, where faculty choose to publish is an even more important metric than what they cite. In her study, she uses source publication as the primary metric for generating information about how well the library is serving faculty in nanoscience. As she states, "publication in a journal was chosen as the best indication of its importance to Penn State faculty since publishing implies not only that faculty read the journal, but also that faculty respect the journal" ${ }^{10}$. Furthermore, Duy and Vaughan note that what faculty cite correlates with use, stating that results from their study "indicate that local journal citation data significantly correlate with electronic journal usage" $" 11$. Therefore, in choosing one metric, source titles of faculty publications is a good indicator not only of what faculty cite, but also what they use at the local library level.

There is an additional advantage to using source title of faculty publications as an assessment metric. As Hughes notes, "Through thorough examination of [the faculty's] publications lists, the librarian learned about each faculty member's particular research interests. This information is extremely useful for the liaison responsibilities of the librarian, since it allows [him or her] to interact knowledgeably with... faculty"12. Such a method allows librarians to become more knowledgeable of both the collection and faculty research areas.

This study will contribute to the existing literature by building on the relatively small number of studies that examine where faculty publish, especially in engineering. Among the relatively few citation studies that specifically examine where faculty publish (Davis ${ }^{13}{ }^{\text {Hughes }}{ }^{12}$; Lascar \& Mendelsohn ${ }^{9}$; LaBonte ${ }^{10}$ ), even fewer address engineering specifically (Salisbury \& Smith ${ }^{14}$; Tucker $^{15}$; Wilson \& Tenopir ${ }^{16}$ ). Several of these researchers explain the importance of having local-level data to inform their collection decisions. For example, as Hughes mentions, "by heavily favoring journals valued by Penn State faculty, as reflected in publications and citings, this study took into account the particular research interests of Penn State faculty"12. None of the existing studies examines the subject areas - mechanical and civil engineering - covered in the current study. Also, only one of the previous citation studies examining faculty source titles gathers data from more than one institution (Davis' study compares across two institutions: Cornell and University of Wisconsin-Madison ${ }^{13}$ ). A second way the current study contributes to the literature is by providing a list of top source titles across four institutions in the fields of mechanical and civil engineering as past studies have compiled for various other disciplines such as Hughes for molecular and cellular biology ${ }^{12}$, LaBonte for nanoscience ${ }^{10}$, Lascar and Mendelsohn for structural biology ${ }^{9}$, Salisbury and Smith for STEM-related subjects ${ }^{14}$, and Tucker for various fields including engineering ${ }^{15}$. 
The current study contributes to the literature by asking the following questions:

- What percentage of publications by mechanical and civil engineering faculty at our respective universities, as indexed in WoS, are held by our libraries?

- Among the missing titles in our libraries, what type of publications are they?

- What are the top source titles in civil and mechanical engineering, as indexed in WoS, across the four universities?

Answers to these questions allow the libraries involved to determine, with a great deal of specificity, what gaps exist between where faculty publish and what the library holds.

\section{Context}

The Sexton Design \& Technology Library is one of five libraries at Dalhousie University (Dal) in Halifax, Nova Scotia. It is located on the downtown Sexton Campus, and serves the faculties of Architecture, Engineering and Planning. A small campus with approximately 2,500 students within those faculties, it makes up about $15 \%$ of Dal's total enrollment of approximately 17,000 students. Dal's Department of Civil and Resource Engineering is comprised of 19 professors and 7 adjunct professors, while the Mechanical Engineering Department is comprised of 12 professors and 7 adjunct professors.

Woodward Library at the University of British Columbia (UBC) in Vancouver, British Columbia serves the faculties of Applied Science, Dentistry, Forestry, Land \& Food Systems, Medicine, and Science. The approximately 6,500 undergraduate and graduate engineering students make up about $13 \%$ of the total approximate student population of 50,000 students on this campus. UBC's Department of Civil Engineering is comprised of 32 full-time faculty members, 16 professors emeriti, and 16 adjunct professors, while the Department of Mechanical Engineering is comprised of 39 full-time faculty members, 10 professors emeriti, and 7 adjunct professors.

The Schulich Library of Science and Engineering is the second largest library of a 12-branch library system at McGill University (McGill) in Montreal, Quebec. It primarily serves undergraduate and graduate students as well as faculty in science and engineering. 4,600 of the 32,000 undergraduate and graduate students enrolled at McGill are in the Faculty of Engineering. McGill's Department of Civil Engineering and Applied Mechanics is comprised of 22 full-time faculty members, and 10 adjunct professors, while the Department of Mechanical Engineering is comprised of 40 faculty members, including professors emeriti, and adjunct professors.

The Engineering \& Computer Science Library is one of 44 libraries at the University of Toronto (UofT), the top ranked library system in Canada and third in North America ${ }^{17}$. It primarily serves faculty, staff and students from the Faculty of Applied Science \& Engineering, as well as the Department of Computer Science from the Faculty of Arts \& Science. There are approximately 
4560 undergraduate and 1756 graduate students (FTEs) in the Faculty of Applied Science and Engineering. UofT's Department of Civil and Mineral Engineering is comprised of 37 professors, and 26 professors emeriti, while the Department of Mechanical and Industrial Engineering is comprised of 58 professors, and 19 professors emeriti.

\section{Methods}

One abstracting and indexing database -WoS Core Collection - was used to retrieve a comprehensive list of our publications from researchers in two engineering areas - civil engineering and mechanical engineering. WoS is a unique database, since it captures all authors' affiliations and has good authority files for these affiliations. We also planned to use Compendex data in this analysis, as the database captures a more complete picture of faculty conference papers. However, we found the data to be less organized and controlled, so it could not be analyzed during the time allocated for this study. Not using Compendex is definitely a limitation for our results.

The following collections are included in our universities' WoS subscription -- Science Citation Index Expanded (SCI-EXPANDED), 1899-present; Social Sciences Citation Index (SSCI), 1956-present; Arts \& Humanities Citation Index (A\&HCI), 1975-present; Conference Proceedings Citation Index-Science (CPCI-S), 1990-present; and Conference Proceedings Citation Index-Social Science \& Humanities (CPCI-SSH), 1990-present (the data file was last updated on 2014-12-12). All searches were performed in January 2015.

Since there are four large engineering schools included in this study - Dal, UBC, McGill, and UofT, the names of the appropriate engineering departments vary. For example, at UofT, there is a department of Mechanical and Industrial Engineering, while at Dal, McGill, and UBC, the department is called Mechanical Engineering. Dal has a department of Civil and Resource Engineering, McGill has a department of Civil Engineering and Applied Mechanics, and UofT and UBC have departments of Civil Engineering. We accommodate these differences in WoS by searching in the address field and using the WoS SAME command to search for the name of the department and the name of the university in the same line of the address field.

Figure 1 demonstrates searching WoS for the Department of Civil Engineering at UBC between 2008 and 2013. We repeated this search for both departments at each institution and exported all results to a text tab delimited file.

We have done the same for mechanical engineering in the Address field in WoS:

- univ British Columbia SAME Mech 
Figure 1: WoS search for civil engineering papers in UBC between 2008 and 2013
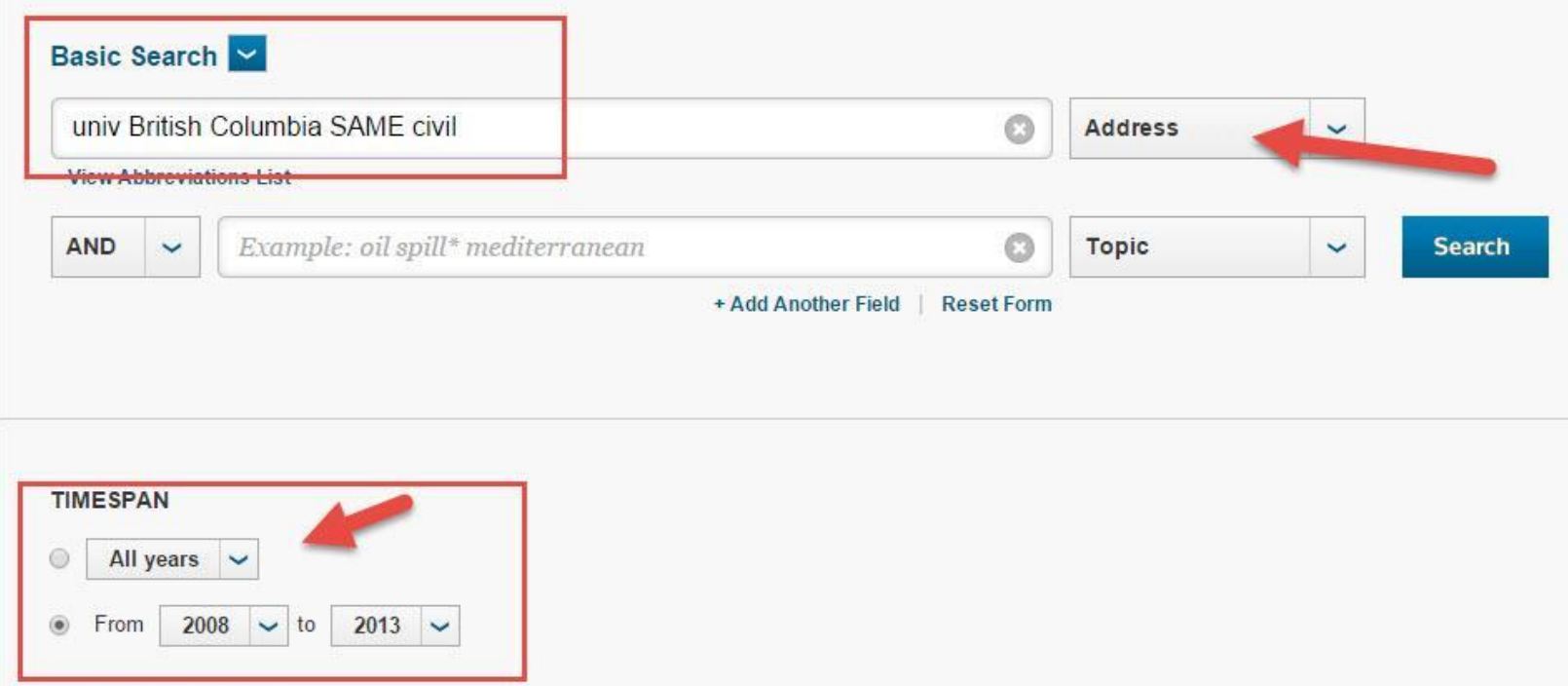

MORE SETTINGS

Interestingly, the searches for a full department name (e.g. univ British Columbia SAME civil engn) recall less results than a less specific search for a discipline (e.g. univ British Columbia SAME civil). This could be due to the authors not consistently including engineering (or engn) in their departmental affiliations.

For those searches that yielded more than 500 results, records were exported from WoS 500 items at a time and later combined in one Excel worksheet. Please see all our data available in the UBC research data depository - Dataverse:

Barsky, Eugene; Dooley, Sarah Jane ; Mawhinney, Tara ; Saundry, Amber; Spence, Michelle, 2015, "Minding the gaps: Comparing research output and library holdings at four large universities", http://hdl.handle.net/11272/10106 V9 [Version]

After combining the data, we could focus on the source field (SO) that contained all publication names from each university's authors (Figure 2). 
Figure 2: Displaying all source publications for all UBC papers in MS Excel

\begin{tabular}{|c|c|c|}
\hline Source Name & UBC Owns? & Notes \\
\hline 2009 3RD INTERNATIONAL CONFERENCE ON BIOINFORMATICS AND BIOMEDICAL ENGINEERING, VOLS 1-11 & YES & \\
\hline 2ND INTERNATIONAL RILEM CONFERENCE ON STRAIN HARDENING CEMENTITIOUS COMPOSITES (SHCC2-RIO) & YES & Freely available after free registration with RILEM \\
\hline ACCIDENT ANALYSIS AND PREVENTION & YES & \\
\hline ADVANCED ENGINEERING INFORMATICS & YES & \\
\hline ADVANCES IN MATERIALS SCIENCE AND ENGINEERING & YES & \\
\hline ADVANCES IN PERFORMANCE-BASED EARTHQUAKE ENGINEERING & YES & Springer ebook \\
\hline APPLIED CLAY SCIENCE & YES & \\
\hline APPLIED MECHANICS REVIEWS & NO & Online access until 1999 \\
\hline AQUATIC SCIENCES & YES & \\
\hline ATMOSPHERIC ENVIRONMENT & YES & \\
\hline AUTOMATION IN CONSTRUCTION & YES & \\
\hline BALTIC JOURNAL OF ROAD AND BRIDGE ENGINEERING & NO & \\
\hline BEHAVIORALECOLOGY & YES & \\
\hline BIORESOURCE TECHNOLOGY & YES & \\
\hline BMC PUBLIC HEALTH & YES & \\
\hline BULLETIN OF THE SEISMOLOGICAL SOCIETY OF AMERICA & YES & \\
\hline CANADIAN GEOTECHNICAL JOURNAL & YES & \\
\hline CANADIAN JOURNAL OF CIVIL ENGINEERING & YES & \\
\hline CARBONATES AND EVAPORITES & YES & \\
\hline CEMENT \& CONCRETE COMPOSITES & YES & \\
\hline CHEMICAL ENGINEERING JOURNAL & YES & \\
\hline CHEMICAL ENGINEERING SCIENCE & YES & \\
\hline CHEMICAL GEOLOGY & YES & \\
\hline CHEMOSPHERE & YES & \\
\hline
\end{tabular}

We then sorted these source titles alphabetically and removed duplicates to receive a final data set for analysis. We later compared the list with the four libraries' current access to journals and conferences to determine what percentage of the source titles were held by the specific university library.

\section{Results}

\section{Coverage of titles}

The civil and mechanical engineering source titles were analyzed for each institution individually against their library's current availability; the results can be found in Table 1 (civil engineering) and Table 2 (mechanical engineering).

Table 1: Percentage of source title coverage for civil engineering department publications in WoS (2008-2013)

\begin{tabular}{lcccc}
\hline Institution & \# of articles & \# of titles & \# of subscriptions & \% coverage \\
\hline Dalhousie University & 241 & 120 & 96 & $80 \%$ \\
McGill University & 310 & 144 & 130 & $90.3 \%$ \\
University of British Columbia & 433 & 169 & 155 & $91.7 \%$ \\
University of Toronto & 547 & 200 & 182 & $91 \%$ \\
\hline
\end{tabular}


Table 2: Percentage of source title coverage for mechanical engineering department publications in WoS (2008-2013)

\begin{tabular}{lcccc}
\hline Institution & \# of articles & \# of titles & \# of subscriptions & \% coverage \\
\hline Dalhousie University & 145 & 84 & 73 & $86.9 \%$ \\
McGill University & 847 & 329 & 278 & $84.5 \%$ \\
University of British Columbia & 673 & 306 & 275 & $89.9 \%$ \\
University of Toronto & 1416 & 596 & 532 & $89.3 \%$ \\
\hline
\end{tabular}

As expected, due to differences in department size across institutions, there was high variation in the number of articles found within this time period. We thus chose to look at the percentage of coverage of each institution's holdings as a comparable measure.

Overall coverage of civil engineering titles was strong, with three institutions above $90 \%$. Mechanical engineering coverage was slightly lower, with three institutions above $85 \%$.

Publication types of source titles not held by the respective library

Publication type was analyzed within source titles not currently held at each institution, to determine if the lacking coverage for each department was primarily journal or conference material. We again looked at percentage for comparison, to allow for differences in departmental size and publication rate.

Within civil engineering, there was a range across institutions in the proportion of journals and conferences (Figure 3). Dal did not hold 24 titles, 8 of which were conferences and 16 of which were journals. UofT did not hold 18 titles, split evenly with between conferences and journals. UBC and McGill each did not hold 14 titles, and had identical counts of 8 conferences and 6 journals. 
Figure 3: Publication types of civil engineering titles not held by each library

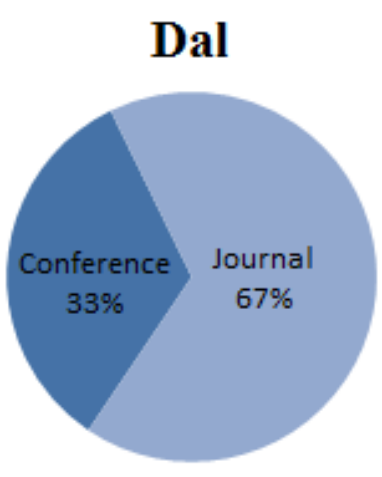

McGill
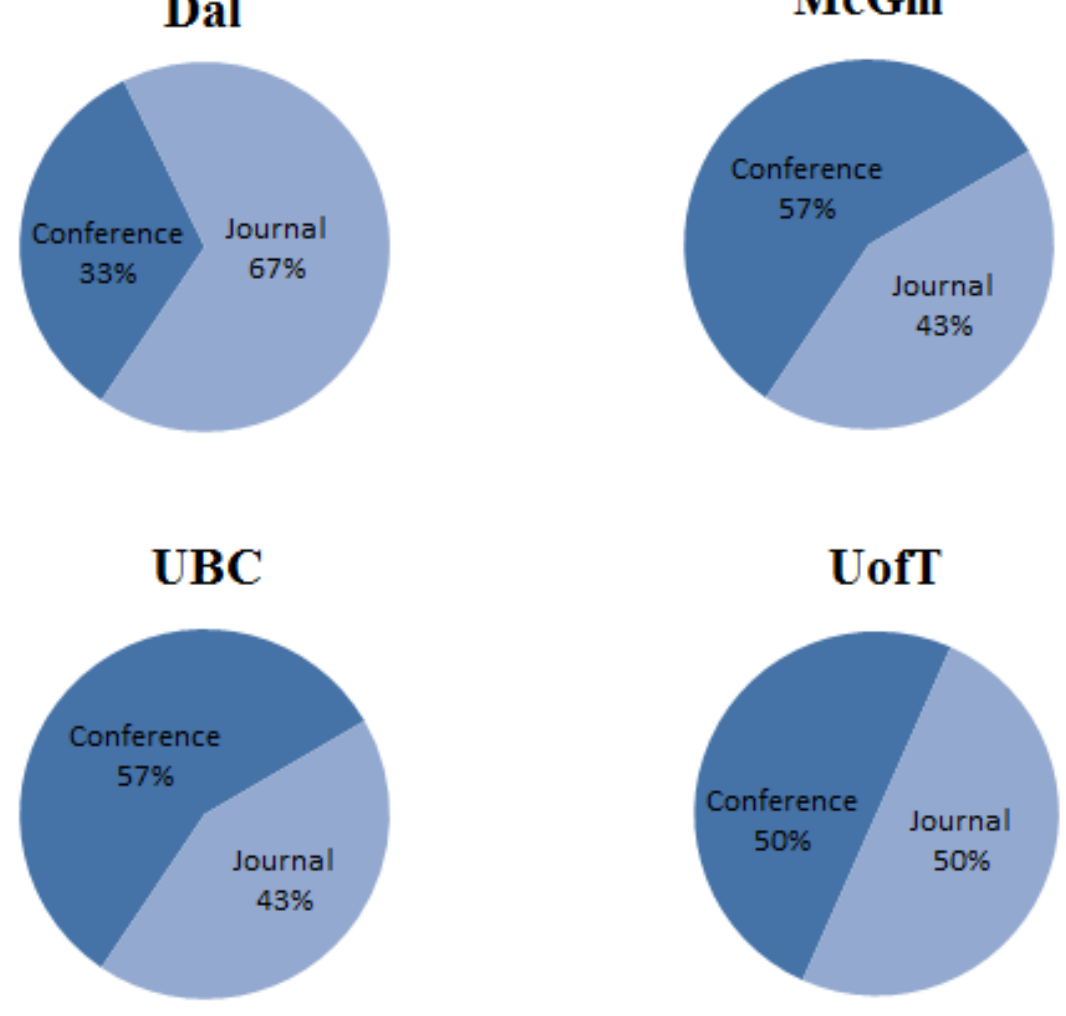

Within mechanical engineering, we found highly variable results in the proportion of each publication type (Figure 4). UofT did not hold 64 titles, composed of 34 conferences and 30 journals. McGill did not hold 51 titles, which included 38 conferences and 13 journals. UBC did not hold 31 titles, of which 25 were conferences and 6 were journals. Dal did not hold 11 titles, 4 of which were conferences and 7 of which were journals. 
Figure 4: Publication types of mechanical engineering titles not held by each library

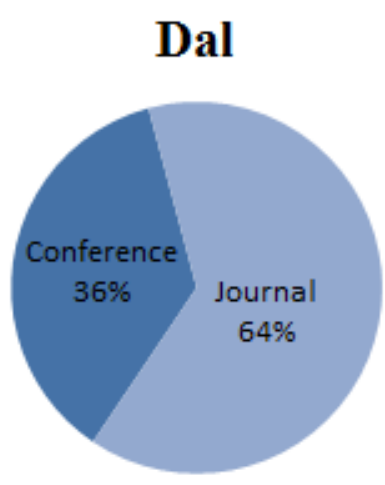

\section{McGill}

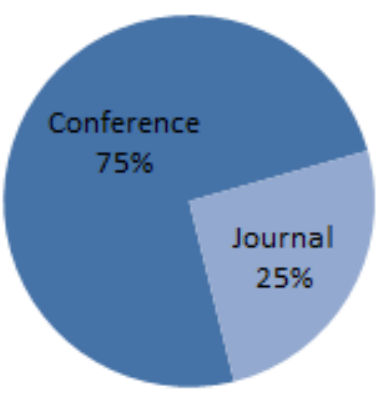

UBC

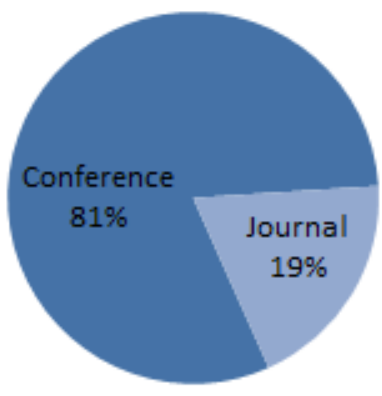

UofT

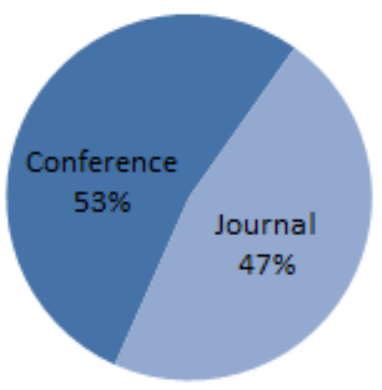

Titles published with highest frequency

In order to determine the titles in which our departments were publishing with the highest frequency, we combined all institution's article lists by department. After calculating the number of occurrences for each source title, we were able to generate a list that indicated the number of times there was a publication in a title during the specified time period. The top ten titles can be found in Table 3 (civil engineering) and Table 4 (mechanical engineering). 
Table 3: Top ten titles in which the civil engineering departments published (2008-2013), and current access at each institution

\begin{tabular}{lccccc}
\hline Source Title & $\begin{array}{c}\text { \# of } \\
\text { articles }\end{array}$ & Dal & McGill & UBC & Uof T \\
\hline Transportation Research Record & 95 & $\checkmark$ & $\checkmark$ & $\checkmark$ & $\checkmark$ \\
Canadian Journal of Civil Engineering & 78 & $\checkmark$ & $\checkmark$ & $\checkmark$ & $\checkmark$ \\
Journal of Structural Engineering-ASCE & 39 & $\checkmark$ & $\checkmark$ & $\checkmark$ & $\checkmark$ \\
Water Research & 34 & $\checkmark$ & $\checkmark$ & $\checkmark$ & $\checkmark$ \\
Canadian Geotechnical Journal & 23 & $\checkmark$ & $\checkmark$ & $\checkmark$ & $\checkmark$ \\
Environmental Science \& Technology & 23 & $\checkmark$ & $\checkmark$ & $\checkmark$ & $\checkmark$ \\
Accident Analysis and Prevention & 23 & $\checkmark$ & $\checkmark$ & $\checkmark$ & $\checkmark$ \\
Journal of Water Supply Research and Technology-Aqua & 21 & $\checkmark$ & $\checkmark$ & $\checkmark$ & $\times$ \\
Earthquake Engineering \& Structural Dynamics & 20 & $\checkmark$ & $\checkmark$ & $\checkmark$ & $\checkmark$ \\
Water Science and Technology & 18 & $\times$ & $\checkmark$ & $\checkmark$ & $\checkmark$ \\
\hline
\end{tabular}

Table 4: Top ten titles in which the mechanical engineering departments published (2008-2013), and current access at each institution

\begin{tabular}{lccccc}
\hline Source Title & $\begin{array}{c}\text { \# of } \\
\text { articles }\end{array}$ & Dal & McGill & UBC & Uof T \\
\hline Journal of Sound and Vibration & 47 & $\checkmark$ & $\checkmark$ & $\checkmark$ & $\checkmark$ \\
Lab on a Chip & 40 & $\checkmark$ & $\checkmark$ & $\checkmark$ & $\checkmark$ \\
Journal of Power Sources & 35 & $\checkmark$ & $\checkmark$ & $\checkmark$ & $\checkmark$ \\
Journal of Applied Physics & 29 & $\checkmark$ & $\checkmark$ & $\checkmark$ & $\checkmark$ \\
Journal of Biomechanics & 28 & $\checkmark$ & $\checkmark$ & $\checkmark$ & $\checkmark$ \\
Journal of Micromechanics and Microengineering & 25 & $\checkmark$ & $\checkmark$ & $\checkmark$ & $\checkmark$ \\
Journal of Fluid Mechanics & 23 & $\checkmark$ & $\checkmark$ & $\checkmark$ & $\checkmark$ \\
Journal of Applied Polymer Science & 22 & $\checkmark$ & $\checkmark$ & $\checkmark$ & $\checkmark$ \\
Energy \& Fuels & 21 & $\checkmark$ & $\checkmark$ & $\checkmark$ & $\checkmark$ \\
Composite Structures & 21 & $\checkmark$ & $\checkmark$ & $\checkmark$ & $\checkmark$ \\
\hline Nof Journal of Non-Newtoninn Fluc Mechanicsaso & & & & \\
\hline
\end{tabular}

Note: Journal of Non-Newtonian Fluid Mechanics also had 21 articles, but as all were UBC publications, the title was excluded from this table. 
It was found that not all institutions had articles published within the top ten titles for each department during our six-year time period. McGill and UBC held current access to all top ten titles for civil engineering. Dal and UofT only lacked access to one title each, Water Science and Technology and Journal of Water Supply Research and Technology-Aqua, respectively. All four institutions had current access to all the top ten titles in which mechanical engineering departments published.

\section{Discussion/Conclusion}

The primary goal of this study was to identify what percentage of mechanical and civil engineering publications at our universities, as indexed in WoS, were held by our respective libraries. Despite pressing financial considerations, each of the libraries studied had at minimum $80 \%$ coverage of the resources in which their respective faculty were publishing. For items that were not owned or subscribed to by the libraries, many of the items were conference proceedings. An aggregation of the top titles across all four institutions resulted in only journals being listed for both disciplines. There are only two journals in the top ten for civil engineering where there is an institution that does not have a current subscription, and all of the institutions had a current subscription to all of the journals in the top ten for mechanical engineering. These findings highlight areas for possible collection expansion, as faculty from UofT and Dal are publishing in journals that their respective libraries aren't subscribing to.

Familiarizing ourselves with where our faculty are publishing was one of the major advantages of this study. Becoming more familiar with our faculty's research, including where they are publishing helps us to better understand their research needs, and determine what areas we should focus our efforts on when collecting. It is important to note that conferences were treated as individual records for each year of the conference. One way the study could be useful is for us to examine conferences to see how many of them are unique and recur in our lists for different years. Buying these important conferences yearly could have a big impact by allowing us to greatly increase the number of holdings where our faculty are publishing. For example, UBC does not have current ASME conference proceedings, but they are often requested and faculty are definitely publishing there. One of the most surprising parts of this study, even though it was found through informal examination of the source titles of the citations gathered, was the variety of journals in which faculty members are publishing. For example, the Journal of Heart Valve Disease and Integrative Biology are not typical mechanical engineering journals, but the research the faculty are doing lends itself well to this type of journal. A potential further area of study is an analysis of the subject areas of the journals and conferences in which faculty are publishing. This information could be used by faculty when they are sharing their research output. It illustrates the wide array of research that is being done and the impact their research is having, not only on the field of engineering but on the research community as a whole. 
Another benefit of this study is to help assess the quality of our collections, and the appropriateness for the areas of research occurring at our respective universities. This can be used to defend collections spending, and when assessing the collection for Canadian Engineering Accreditation Board approval, program approval, and for quality assurance processes such as the Council of Ontario Universities' Degree Level Expectations.

A specific benefit of doing this study across multiple institutions (besides collaboration with wonderful colleagues) is that we were able to get a larger sample, and could not only compare results but were able to aggregate the data to produce a top ten list of journals our faculty were publishing in for both subject areas, and compare our individual holdings to that data, giving us additional insights into the status of our collections.

Although all of our institutions' subscriptions to WoS include the Conference Proceedings Citation Index- Science (CPCI-S) --1990-present and the Conference Proceedings Citation Index-Social Science \& Humanities (CPCI-SSH) --1990-present, the coverage of engineering conferences in WoS is still lacking in comparison to engineering databases like Compendex, and there are publications from our faculty that we missed by using WoS exclusively. Wilson and Tenopir, who studied publications from the University of New South Wales, found that conference publications accounted for $52 \%$ of engineering faculty output ${ }^{16}$. The number of conferences where faculty at our four institutions are publishing is likely much higher than the results in WoS indicate. However, we found that WoS offers a more accurate affiliation search than other databases, which was essential to this study. Using other resources, such as Compendex or Scopus, faculty websites or input from faculty could give us a more complete picture of where our faculty are publishing.

While this study was useful to not only assess our institutions' holdings but to display the multidisciplinary nature of the research being conducted at our institutions, as demonstrated by the breadth of journals and conferences in which the faculty members are publishing, it is limited in that it was restricted to only two departments/areas of study. Expanding this study to other areas of engineering will help us to assess our collections and give us another avenue to determine what research our faculty are conducting and where we might need to further collect.

An unintended benefit of this research was the examination of catalogue records at our respective institutions. By inspecting catalogue records for holdings information, we were able to discover numerous cataloguing errors, including incorrect holdings information.

While every effort was made to ensure the accuracy of the results, it is possible that some of the data was coded incorrectly (e.g. coded as if it was not subscribed to even if it was). This could happen due to user error, or if a journal title changed and it was not evident in the catalogue. Sources were coded as a "yes" for owning/subscribing to content only if the subscription was up to date, which might not be evident in the case of title changes. 
Further research could examine the relationship between where faculty publish and what they cite. An additional avenue for this type of research could include a more in-depth examination of the types of publications in which faculty are publishing, such as commercial, non-profit, open access, etc., which would help to determine the cost implications of buying where faculty are publishing as studied by Davis ${ }^{13}$. Looking at dissertations is another possibility and may give us a richer source of information, since they are typically longer and more detailed than research articles.

While the results of this analysis can help us to determine what to purchase, there are limitations. The impact factor or importance of the journals in the respective areas are other factors to consider, for example. Where the journal is indexed may be another consideration ${ }^{12}$. Just because faculty members are publishing in a particular journal does not automatically make that journal a good candidate for purchase. This research does, however, give us a starting place and helps us to understand our faculty's research output and areas for development of the collection, and creates opportunities for feedback and conversations with faculty to hear their opinions and needs in terms of research resources.

\section{Acknowledgements}

The authors wish to thank April Colosimo and Giovanna Badia for their helpful comments on the draft of this paper.

\section{Bibliography}

1. Young, B. (2014). What do engineering researchers cite? A citation analysis study of sixteen engineering journals. Issues in Science \& Technology Librarianship, (75). http://dx.doi.org/10.5062/F44Q7RXF

2. Hoffmann, K., \& Doucette, L. (2012). A Review of citation analysis methodologies for collection management. College \& Research Libraries, 73(4), 321-335. http://dx.doi.org/10.5860/crl-254

3. Currie, L., \& Monroe-Gulick, A. (2013). What do our faculty use? An interdisciplinary citation analysis study. The Journal of Academic Librarianship, 39(6), 471-480. http://dx.doi.org/10.1016/j.acalib.2013.08.016

4. Cusker, J. (2012). Using ISI Web of Science to compare top-ranked journals to the citation habits of a "real world" academic department. Issues in Science \& Technology Librarianship, (70). http://dx.doi.org/10.5062/F40V89RB

5. Kraus, J.R. (2005). Comparing journal use between biology faculty and undergraduate students. Issues in Science \& Technology Librarianship, (43). http://dx.doi.org/10.5062/F4736NVN

6. Price, J.S. (2007). How many journals do we have? An alternative approach to journal collection 
evaluation through local cited article analysis. Serials: The Journal for the Serials Community, 20(2), 134141. http://dx.doi.org/10.1629/20134

7. Ralston, R., Gall, C., \& Brahmi, F.A. (2008). Do local citation patterns support use of the impact factor for collection development? Journal of the Medical Library Association, 96(4), 374-378. http://dx.doi.org/10.3163/1536-5050.96.4.014

8. Rethlefsen, M.L. (2007). Citation analysis of Minnesota Department of Health official publications and journal articles: a needs assessment for the RN Barr Library. Journal of the Medical Library Association, 95(3), 260-266. http://dx.doi.org/10.3163/1536-5050.95.3.260

9. Lascar, C., \& Mendelsohn, L. D. (2001). An analysis of journal use by structural biologists with applications for journal collection development decisions. College \& Research Libraries, 62(5), 422-433. http://dx.doi.org/10.5860/crl.62.5.422

10. LaBonte, K.B. (2005). Citation analysis: a method for collection development for a rapidly developing field. Issues in Science \& Technology Librarianship, (43). http://dx.doi.org/10.5062/F4TX3CB1

11. Duy, J., \& Vaughan, L. (2006). Can electronic journal usage data replace citation data as a measure of journal use? An empirical examination. The Journal of Academic Librarianship, 32(5), 512517. http://dx.doi.org/10.1016/j.acalib.2006.05.005

12. Hughes, J. (1996). Use of faculty publication lists and ISI citation data to identify a core list of journals with local importance. Library Acquisitions: Practice \& Theory, 19(4), 403-413. http://dx.doi.org/10.1016/0364-6408(95)00055-E

13. Davis, P.M. (2002). Where to spend our e-journal money? Defining a university library's core collection through citation analysis. Portal: Libraries and the Academy, 2(1), 155-166. http://dx.doi.org/10.1353/pla.2002.0009

14. Salisbury, L., \& Smith, J.S. (2010). The Use of Web of Knowledge to study publishing and citation use for local researchers at the campus level. Collection Management, 35(2), 69-82. http://dx.doi.org/10.1080/01462671003597959

15. Tucker, C. (2013). Analyzing faculty citations for effective collection management decisions. Library Collections, Acquisitions, and Technical Services, 37(1), 19-33. http://dx.doi.org/10.1016/j.lcats.2013.06.001

16. Wilson, C.S., \& Tenopir, C. (2008). Local citation analysis, publishing and reading patterns: Using multiple methods to evaluate faculty use of an academic library's research collection. Journal of the American Society for Information Science and Technology, 59(9), 1393-1408. http://dx.doi.org/10.1002/asi.20812

17. Association of Research Libraries. (2014). Analytics. ARL Statistics. Retrieved from http://arlstatistics.org/analytics 